\title{
A Novel Multi-loop Fuzzy Logic Dynamic Controller for Wind/Photovoltaic-Grid Interface DC Energy Utilization Farm
}

\author{
A. M. Sharaf ${ }^{1}$, I. H. Altas ${ }^{2}$ and E. Ozkop ${ }^{3}$ \\ ${ }^{1}$ Energy Research Group-UTT, University of Trinidad and Tobago, Trinidad \\ e-mail: adel.sharaf@utt.edu.tt \\ ${ }^{2}$ Dept. of Electrical and Electronics Engineering, Karadeniz Technical University, Turkey \\ e-mail: ihaltas@altas.org \\ ${ }^{3}$ Dept. of Electrical and Electronics Engineering, Karadeniz Technical University, Turkey \\ e-mail: eozkop@ktu.edu.tr
}

\begin{abstract}
This paper proposes a novel control system for control of a hybrid wind/photovoltaic (PV) farm utilization with alternative power source for DC type loads. A controller consisting of six different loop controllers is mainly used to regulate the DC-DC converter to reduce a weighted total sum of all loop errors, to mainly track a given speed reference trajectory depicting the demand for discharge or flow and also to ensure power quality, reliability and stability. The proposed control function is digitally simulated using the MATLAB/Simulink/ SimPower System software environment. The dynamic performance of the hybrid system is examined for the control system validation under normal and abnormal operating conditions.
\end{abstract}

\section{Key words}

Hybrid power system, renewable energy, wind/ photovoltaic system, modelling, planning, control system.

\section{Introduction}

World population has increased and the world has needed more electrical energy depending on this rise. The products quantities that use up electricity have grown rapidly. Fossil fuels have been excessively consumed and the reserves have been rapidly depleted much faster than new ones are being formed for decade year [1]. It seems that conventional energy sources such as hydroelectric power, fossil fuels, and nuclear power will not provide coming generations demands. Due to the national and global issues of air pollution, grid reliability, dependence on foreign oil, climate change, renewable energy resources like solar, wind, micro-hydro, geo-thermal, wind, wave, bio-mass and i.e. are growing in importance. There are many studies about renewable energy source search, utilization and development and thought renewable energy technologies as environmentally sustainable and convenient alternatives.

The cost of generating electricity from the photovoltaic system has already been reduced and a photovoltaic electricity generation system cost may be close to the one of conventional (non-renewable) fossil fuel energies [2]. On the other hand, the solar varies over time and is dependent on environmental conditions (temperature, irradiance, etc.). That combining a photovoltaic generation system with a wind energy conversion system will reduce the zero-power intervals is suggested since sunny days are usually quiet and strong winds are frequently occurred at cloudy days or at nighttimes [3]. Hence, hybrid systems have the potential to arrange undesired conditions.

A hybrid power system (HPS) is an electric power system that includes more than one type of energy conversion systems. There are different types of HPS, which imply different combinations of renewable energy systems (RESs), non-renewable energy systems and storage systems (battery, flywheel, hydrogen/fuel-cell, hydropower etc.) can be used to constitute HPSs [4-6]. HPSs can provide the required power for the connected loads with suitable control and effective coordination between various subsystems. The advantages of nonrenewable and renewable power conversion systems are seen in HPSs. Renewable energy sources provide autonomy from fossil fuel and also fuel prices indirectly and a sustainable power supply future. Non-renewable energy sources are independent from environmental conditions (temperature, irradiance, wind velocity, etc.). The power utilization system safety and reliability can be strengthened to use non-renewable energy sources when the renewable energy sources in situations of deficient environmental circumstances. 
To achieve a hybrid renewable energy generation system, the system should be appropriately designed with taking into consideration economic, reliability, and environmental measures subject to physical and operational constraints/strategies [7,8]. When sizing a hybrid renewable power system, the types and sizes of wind turbine generator, PV panel sizes and the energy storage capacity should be optimized via using proper methods [9]. Numerous large-scale and cost-effective Wind and/or PV commercial and industrial energy utilization have different applications in water pumping, air-conditioning lighting, telecommunications, refrigeration, household-based appliances (TV, blenders, swamp coolers), etc.

The paper is organized as follows. Section 2 defines the configuration and the employed models of the proposed hybrid system. Section 3 presents the wind/photovoltaicgrid interface dc energy utilization controller structure. Section 4 analyzes simulated results of three operation conditions of the proposed hybrid system. Specific conclusions are evaluated in Section 5.

\section{Proposed Hybrid System Configuration}

The proposed hybrid power generation system configuration is shown in Figure 1. The proposed system composed of PV farms, wind turbine generator, alternative power source, $\mathrm{AC} / \mathrm{DC}$ converters, a four quadrant PWM controlled chopper type DC-DC converter, controller and DC loads. In the system, DC loads are feed by the dc voltage which is obtained by the PV farm, wind turbine and also alternative power source. Since a solar is abundant, free, environment-friendly and non-regional, a solar energy is more attractive than prior decade. The solar energy is converted into the electrical energy via a photovoltaic cell combined with each other by parallel and series to get bigger electrical energy. Due to the fact that solar and wind energy source is intermittent and quite variable, longitude, latitude, weather and limited daytime should be considered in acquiring electrical energy from PV system and wind turbine system and also it is possible that power fluctuations can be observed since photovoltaic and wind power source is highly dependent on the weather conditions. The different energy systems (other renewable, non-renewable and also storage energy systems) can be combined with the Wind/PV to increase the efficiency. In the near future using hybrid systems for electricity generation may have more profitable in parallel with the technological advances.

\section{A. DC Motor}

DC motors are usually preferable due to their reliability, durability, low costs, voltage characteristics, positive convention coefficients between electrical and mechanical parts, sizing and design flexibility.

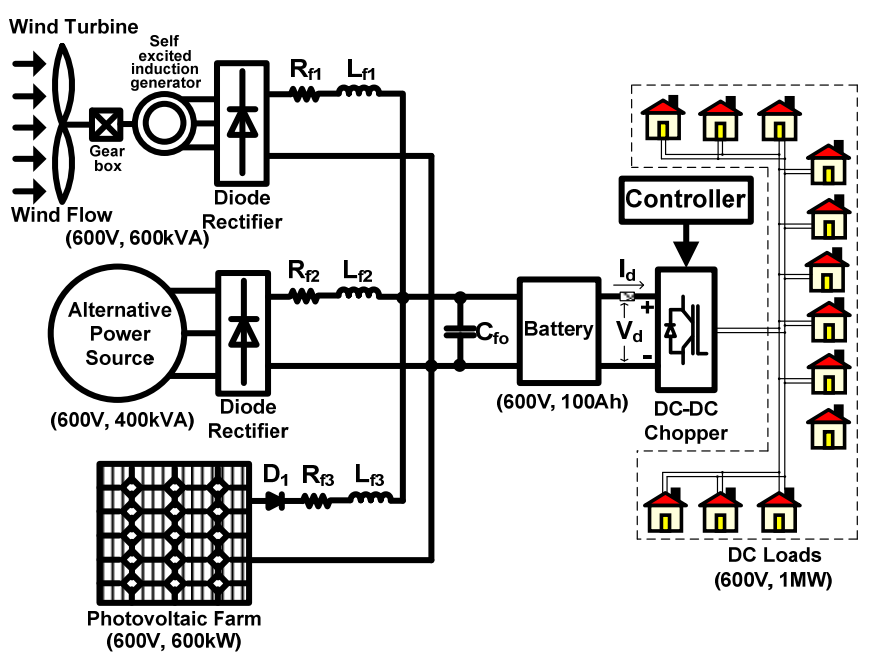

Fig. 1. Proposed grid-connected Wind/PV power generation system.

A permanent magnet dc motor (PMDC) converts electrical power provided by a voltage source to mechanical power provided by a spinning rotor by means of magnetic coupling. The equivalent circuit of a PMDC motor is illustrated in Fig. 2. The parameters and symbols which were used in simulating the system are given in Appendix. The armature coil of the DC motor can be presented by an inductance $\left(\mathrm{L}_{\mathrm{m}}\right)$ in series with resistance $\left(\mathrm{R}_{\mathrm{m}}\right)$ in series with an induced voltage $\left(\mathrm{e}_{\mathrm{m}}\right)$ which opposes the voltage source. A differential equation for the equivalent circuit can be derived by using Kirchhoff's voltage law around the electrical loop.

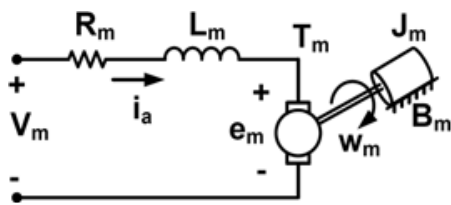

Fig 2. The equivalent circuit of a dc motor

The differential equations into state space form for the armature current and angular velocity can be written as

$$
\frac{d}{d t}\left[\begin{array}{c}
i_{a} \\
\omega_{m}
\end{array}\right]=\left[\begin{array}{cc}
-\frac{R_{m}}{L_{m}} & -\frac{K_{t}}{L_{m}} \\
\frac{K_{t}}{J} & -\frac{B}{J}
\end{array}\right]\left[\begin{array}{c}
i_{a} \\
\omega_{m}
\end{array}\right]+\left[\begin{array}{cc}
\frac{1}{L_{m}} & 0 \\
0 & -\frac{1}{J}
\end{array}\right]\left[\begin{array}{c}
V_{m} \\
T_{l}
\end{array}\right]
$$

The load torque is given by

$$
T_{L}=K_{0}+K_{1} \omega_{m}+K_{2} \omega_{m}^{2}
$$

The nonlinear inertia $\mathrm{J}$ and viscous friction $\mathrm{B}$ have the following variable non-linear forms:

$$
\begin{aligned}
& B_{m}=B_{0}+B_{1} \omega_{m}+B_{2} \omega_{m}^{2} \\
& J_{m}=J_{0}+J_{1} \omega_{m}+J_{2} \omega_{m}^{2}
\end{aligned}
$$

Where, the coefficients are chosen as given in Appendix. 


\section{B. Photovoltaic Farm System}

The PV power has many advantages like a short lead time to design and install, high energy density, no noise and $\mathrm{CO}_{2}$ emission, long life time, highly mobile and portable, minimal maintenance requirement $[10,11]$. Every PV array consists of many solar cells. A solar cell consisting of a $\mathrm{p}-\mathrm{n}$ junction formed by semiconductor converts energy into electrical energy directly. The light energy generates an electron-hole pair during sunlight falls on a solar cell. The electron-hole pair is diverged with the hole towards the p-region and the electrons drifting towards the n-region by the electric field made in the junction and a voltage is generated at the output [12]. There are two most common used models of PV cell, one diode equivalent five parameters and four parameters circuit mode [13]. In this application, four parameters, which are functions of solar irradiance, load current and temperature, circuit model is realized. The arranged equivalent circuit model is shown in Figure $3[14,15]$.

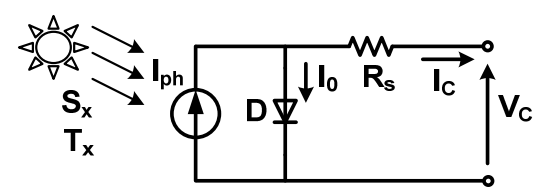

Fig. 3. One diode equivalent parameters PV model.

The PV array equivalent circuit was modelled as a single block called PVA Model. This model simulates the characteristic of the solar panel with the equation given in $[14,15]$.

\section{Wind Turbine Energy Conversion System}

The wind energy was used to sail ships for the first time and then grind grains and pump water. Later on, at the beginning of the $1900 \mathrm{~s}$, the windmill was installed to generate electricity in the rural area [10]. At present, wind energy is extensively used in either stand-alone applications or grid-connected electric generation systems.

In the case of a grid-connected system there is a connection between the renewable system and the local electricity network. The system can be used to provide part of the urgent needed electricity or export electrical energy to the networks when the local need is low. Renewable energy systems must provide high quality power, guarantee safe interaction with the grid, and be protected from abnormal operating conditions to combine properly with utility grid $[4,16]$. Stand-alone system is independent of the local electricity network and also often used in areas without local electricity distribution net. In many applications, wind energy systems are combined with the other renewable energy systems like a photovoltaic, tidal, fuel cell, micro hydro, etc [17]. Wind farms are constituted via that many wind turbines are generally positioned near each others. A stand-alone wind conversion system scheme is consisted of wind turbine, gear box and electrical generator. Different types of electrical machines used for electrical power generation, i.e. squirrel cage induction generator, wound rotor (known as doubly-fed) induction generator (DFIG), permanent magnet synchronous generator [18]. In this study, a self excited induction generator is used. The electrical generator rotor consisting of two or more blades generates kinetic energy by wind blowing and the wind turbine captures this energy. The turbine is mounted on tall tower to enhance the energy capture.

\section{Battery}

A battery storing energy in the electrochemical form is widely used device for energy storage in the many applications such as electric vehicle and renewable energy systems. By the reason of an intermittent feature of solar and wind, the renewable energy systems need the energy storage to feed the loads without undesirable disturbances and to ensure stability, power quality and reliability [19]. There are many types of rechargeable batteries used in variable applications such as lead-acid (Pb-acid), nickel-cadmium (NiCd), nickel-metal hydride (NiMH), lithium-ion (Li-ion), lithium-polymer (Li-poly) and zinc-air [20]. During the battery design for the renewable energy system, the following system requirements should be taken in consideration [20-21]: Voltage and current; Charge and discharge rates and duration; Operating temperature during charge and discharge; Life in number of charge and discharge cycles; Cost, size, and weight constraints.

\section{E. Alternative Power Source}

The alternative power source is used to help support the system when the Wind/PV farm hybrid renewable energy system power is not enough to provide energy through the DC loads.

\section{Controller Structure}

The proposed controller scheme is shown in Figure 4. The controller arranges the DC loads power flow. The controller consists of two different tri-loop controllers. There are Controller A and Controller B controllers. The motor speed $\left(\mathrm{w}_{\mathrm{m}}\right)$, common DC bus current $\left(\mathrm{I}_{\mathrm{d}}\right)$ and moment consisted of the Controller A inputs. Each input error is obtained by taking the difference between the real and reference input values except for the moment. The moment input error is obtained by taking the difference between the real and delayed real input values. The motor speed error, the common DC current error and the moment error are multiplied by the related weight factors $\left(\gamma_{\mathrm{w}}, \gamma_{\mathrm{I}_{\max }}\right.$ and $\left.\gamma_{\mathrm{m}}\right)$ and the output summations is a total Controller A error $\left(e_{t_{1}}\right)$. The tri-loop error is multiplied by a weight factor $\left(\mathrm{K}_{1}\right)$. The common DC bus current $\left(\mathrm{I}_{\mathrm{d}}\right)$, common DC bus voltage $\left(\mathrm{V}_{\mathrm{d}}\right)$ and common DC bus power constitute the Controller B inputs. Every input error is obtained by taking the difference between the real and delayed real input values. The common DC bus current error, the common DC bus voltage error and the power error multiplied by the related weight factors $\left(\gamma_{I_{d}}, \gamma_{V_{d}}\right.$ and $\left.\gamma_{P_{d}}\right)$ and the output summations is a total 
Controller $\mathrm{B}$ error $\left(e_{t_{2}}\right)$.The tri-loop error is multiplied by a weight factor $\left(\mathrm{K}_{2}\right)$.

The summation of the tri-loop errors (Controller A, Controller B) forms a global error. The global error goes into fuzzy logic controller (FLC) block. FLC, which is designed to eliminate the need for continuous operator attention and used automatically to adjust some variables the process variable is kept at the reference value. The main fuzzy reasoning blocks and the defuzzification process of the FLC used in this study are given in Figure 5. The FLC used here is developed in Matlab/Simulink environment for multi purpose use as a control tool. With some simple modifications it can be used to control different systems. More detailed information about the Matlab/Simulink modeling of the FLC used here can be found in $[22,23]$.

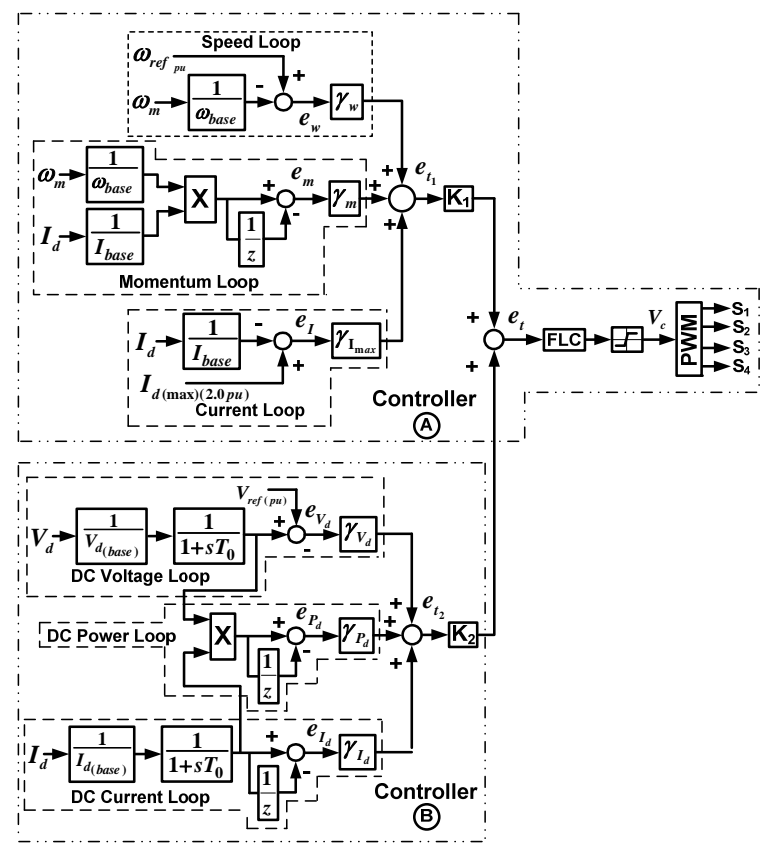

Fig. 4. Six-loop dynamic error driven fuzzy logic controller.

After the signal is processed in the block, the FLC output signal goes into PWM block and the block generates four pulses. The pulses are fed to the four quadrant DC-DC chopper. The loads voltage is controlled by adjusting the switching functions for the chopper switches. Then an obtained voltage $\mathrm{V}_{\mathrm{m}}$ is used as a motor input voltage. The weight factors and FLC constants values are given in Appendix. The proposed system was digitally simulated by using the MATLAB/Simulink/SimPower software and is shown in Figure 6.

\section{Simulation Results}

To validate the multi-loop Fuzzy Logic Dynamic Control scheme, three different speed reference trajectories for the PMDC motorized loads were tested.

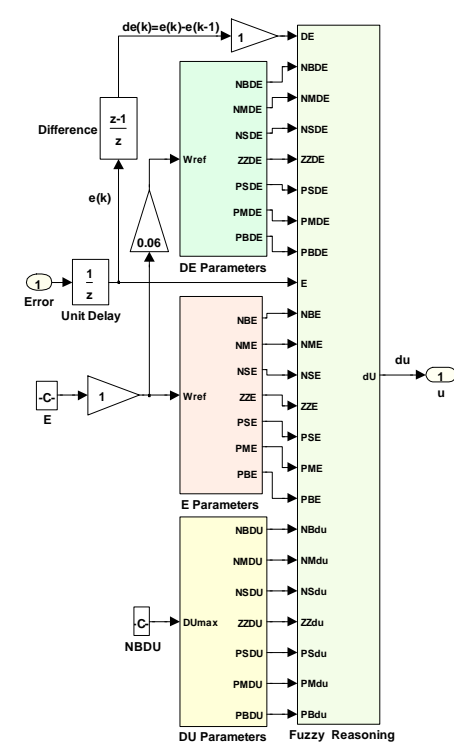

Fig. 5. Details of the fuzzy reasoning block.

One of the speed reference in time increases linearly and reaches the $400 \mathrm{rad} / \mathrm{s}$ at the end of the first 0.5 seconds, and then the reference speed remains speed constant during 1.0 seconds. At 1.5 th second, the reference speed decreases with same slope as at the first 0.5 seconds. After 2.0 second, the load speed changes the direction and load motor increases its speed through the reverse direction. At 2.5th second, the reference speed reaches the $-400 \mathrm{rad} / \mathrm{s}$ and remains this speed at the end of 3.5th second and then the reference speed decreases and becomes zero at fourth second. This reference speed waveform is named as Type I and the concerning simulation results are shown in Figure 7-12 in this study.

\section{Conclusion}

The paper presents a digital model and validation study of a green renewable Wind/PV-powered Farm with DC type motorized loads using novel controller. In the hybrid power generation system, different power systems are connected the systems together and complement one another to serve the load to fulfill certain economic, environmental, and reliability criteria. The control strategy is based on source-load matching that is fully suitable for hybrid wind/photovoltaic farm with alternative interface connection to the local electric grid.

The dynamic controller scheme is mainly used to regulate the DC-DC converter and also to control power flow from power sources to reduce a weighted total sum of all loop errors and to mainly track a given speed reference trajectory depicting the demand for discharge or flow. The real inherent nonlinearity of motor and mechanical load inertia, viscous friction as well as any load torque excursions are all modelled as nonlinear functions of the motor speed. The proposed novel control scheme has been validated for both effective and good dynamical speed reference trajectory tracking with enhanced power/energy utilization. 


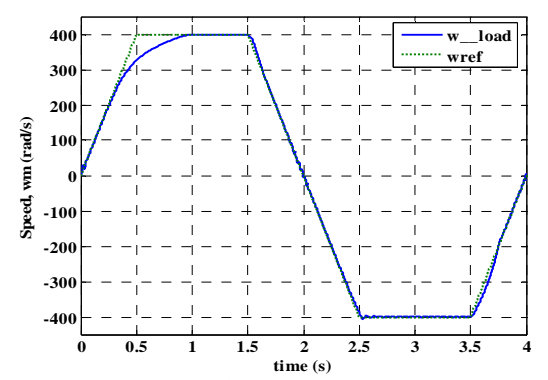

Fig.7. Speed waveform (Type I)

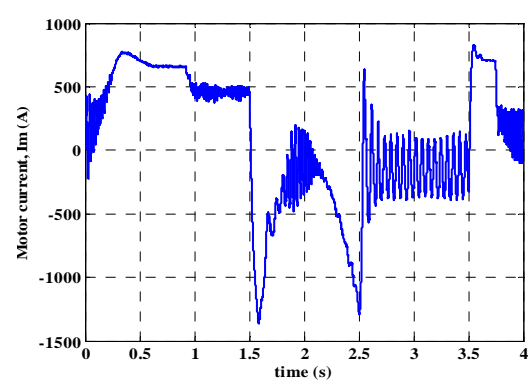

Fig.8. Motor current waveform (Type I)

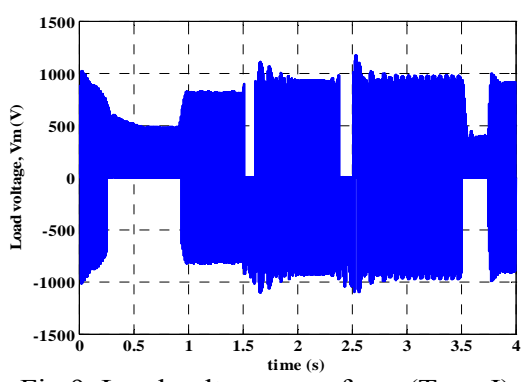

Fig.9. Load voltage waveform (Type I)

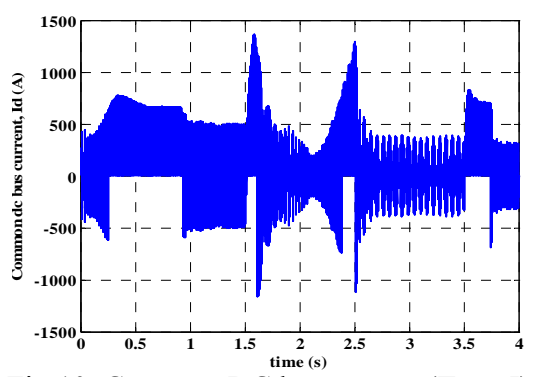

Fig.10. Common DC bus current (Type I)

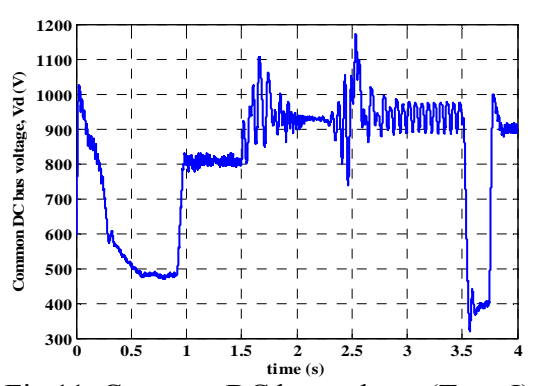

Fig.11. Common DC bus voltage (Type I)

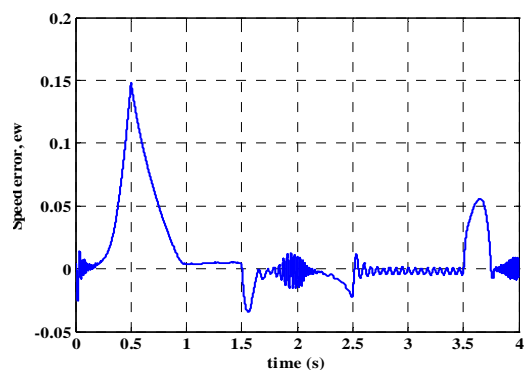

Fig.12. Speed error waveform (Type I)

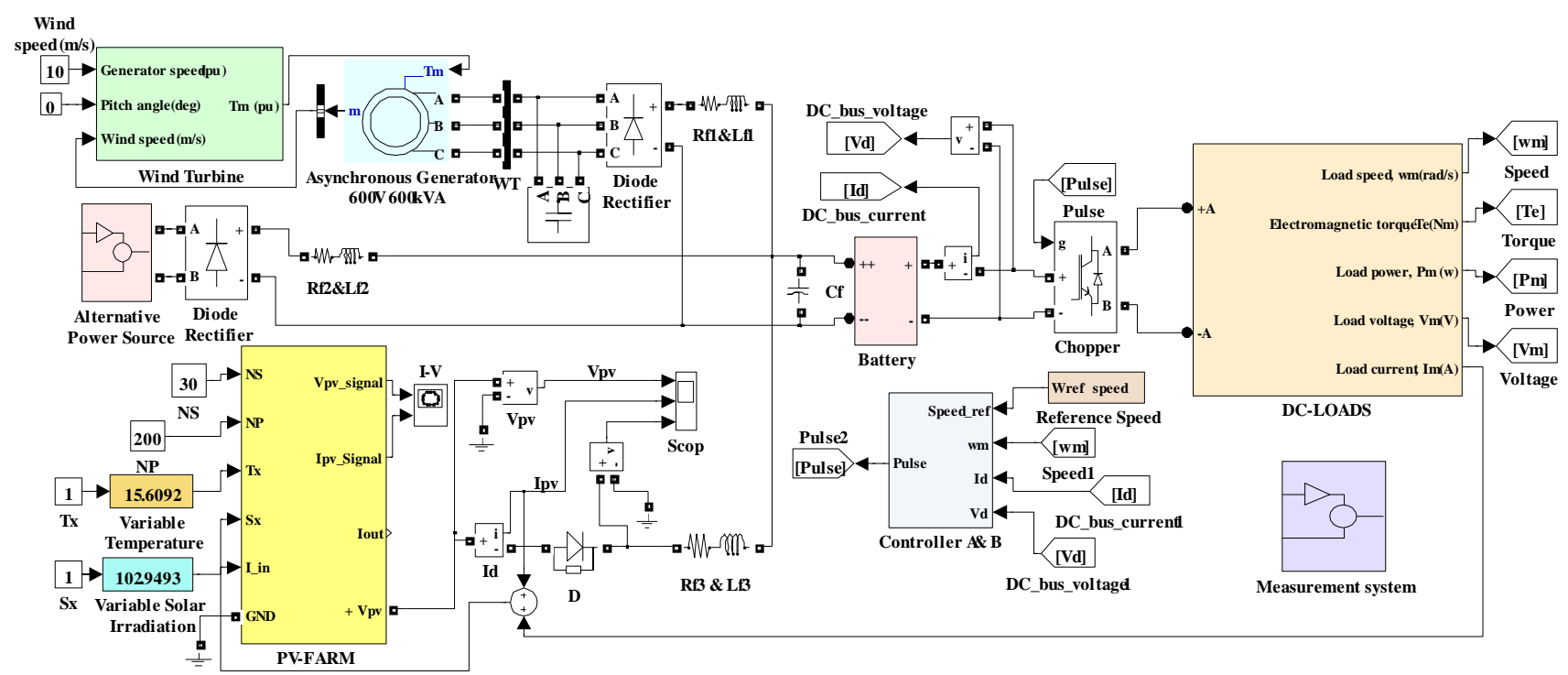

Fig. 6. The proposed hybrid renewable energy system Simulink block diagram.

\section{Appendix}

\section{A.1Simple Wind Turbine Model (Quasi-static model)}

$T_{W}=\frac{1}{2 \lambda} \rho A R C_{P} V_{W}^{2}=\frac{1}{2 \omega_{W}} \rho A C_{P} V_{W}^{3}=k \frac{V_{W}^{3}}{\omega_{W}}$

Where

$\rho$ is the specified density of air $\left(1.25 \mathrm{~kg} / \mathrm{m}^{2}\right)$

$A$ is the area swept by the blades

$R$ is the radius of the rotor blades

$C_{P}$ is power conversion coefficient

$\lambda$ is the tip speed ratio

$\omega_{W}$ is the wind turbine velocity in rpm

$k$ is equivalent coefficient in per unit $(0.745)$

\section{A.2 Induction Generator}

3 phase, 2 pairs of poles, $\mathrm{V}_{\mathrm{g}}=600 \mathrm{kV}(\mathrm{L}-\mathrm{L}), \mathrm{Sg}=600$ KVA,

Cself $=75 \mathrm{uF} /$ Phase

$$
R_{s}=0.016, L_{l s}=0.06, R_{r}^{\prime}=0.015, L_{l r}^{\prime}=0.06
$$

$L_{m}=3.5, H=2, F=0, p=2$ 


\section{A.3 Load and controller parameters}

\begin{tabular}{|c|c|c|}
\hline Voltage source & $\mathrm{V}_{\mathrm{m}}$ & $600 \mathrm{~V}$ \\
\hline Inductance & $\mathrm{L}_{\mathrm{m}}$ & $10 \mathrm{mH}$ \\
\hline Resistance & $\mathrm{R}_{\mathrm{m}}$ & $0.32 \Omega$ \\
\hline Induced voltage & $\mathrm{e}_{\mathrm{m}}$ & $\mathrm{V}$ \\
\hline Actual rated speed & $\mathrm{W}_{\mathrm{a} \text {-rated }}$ & $600 \mathrm{rad} / \mathrm{s}$ \\
\hline Back emf constant & $\mathrm{K}_{\mathrm{e}}$ & $0.1 \mathrm{~V} . \mathrm{s} / \mathrm{rad}$ \\
\hline Electromagnetic torque & $\mathrm{T}_{\mathrm{e}}$ & $\mathrm{Nm}$ \\
\hline Motor speed weighting factor & $\gamma_{\mathrm{w}}$ & 10 \\
\hline $\begin{array}{l}\text { Common DC bus current } \\
\text { weighting factor }\end{array}$ & $\gamma_{\mathrm{I}_{\max }}$ & 0.1 \\
\hline Moment weighting factor & $\gamma_{\mathrm{m}}$ & 0.01 \\
\hline Bus current weighting factor & $\gamma_{I_{d}}$ & 0.1 \\
\hline $\begin{array}{l}\text { Common DC bus power } \\
\text { weighting factor }\end{array}$ & $\gamma_{\mathrm{P}_{\mathrm{d}}}$ & 0.1 \\
\hline $\begin{array}{l}\text { Common DC bus voltage } \\
\text { weighting factor }\end{array}$ & $\gamma_{v_{d}}$ & 0.1 \\
\hline \multicolumn{3}{|c|}{$\begin{array}{l}\text { Controller A \& Controller B weight factors } \\
\qquad \mathrm{K}_{1}=\mathrm{K}_{2}=1\end{array}$} \\
\hline \multicolumn{3}{|c|}{$\begin{array}{c}\text { Input filters } \\
\mathrm{R}_{\mathrm{f}}=0.025 \Omega, \mathrm{L}_{\mathrm{f}}=0.005 \mathrm{H}, \mathrm{C}_{\mathrm{f}}=20000 * 10^{-6} \mathrm{~F}\end{array}$} \\
\hline \multicolumn{3}{|c|}{$\begin{array}{c}\text { Load torque constants } \\
\mathrm{K}_{0}=0.9, \mathrm{~K}_{1}=3.9 * 10^{-3}, \mathrm{~K}_{2}=66^{*} 10^{-6}\end{array}$} \\
\hline \multicolumn{3}{|c|}{$\begin{array}{c}\text { Viscous friction constants } \\
\mathrm{B}_{0}=5.7 * 10^{-3}, \mathrm{~B}_{1}=25^{*} 10^{-6}, \mathrm{~B}_{2}=0.423 * 10^{-6}\end{array}$} \\
\hline $\begin{array}{c}\text { Rotor moment of } \\
\mathrm{J}_{0}=14.44 * 10^{-3}, \mathrm{~J}_{1}=62 .\end{array}$ & $\begin{array}{l}\mathrm{a} \text { consta } \\
, \mathrm{J}_{2}=1.0\end{array}$ & \\
\hline
\end{tabular}

\section{References}

[1] WEC, "Deciding the future: Energy policy scenarios to 2050", World Energy Council, September, 2007.

[2] REN21 "Renewables 2007 global status report", REN21, 2008 Deutsche Gesellschaft für Techniche Zusammenarbeit (GTZ) GmbH, 2007.

[3] M. Qiang, W. Wei-yang and Zhen-lin, "A multi-directional power converter for a hybrid renewable energy distributed generation system with battery storage", CES/IEEE $5^{\text {th }}$ International Power Electronics and Motion Control Conference, IPEMC 2006, August, Vol. 3, pp. 1-5.

[4] C. Wang, L. Wang, L. Shi and Y. Ni, "A survey on wind power technologies in power systems", IEEE Power Engineering Society General Meeting 2007, Tampa, FL, USA, 24-28 June.

[5] L. Wang and K.H. Liu, "Implementation of a web-based real-time monitoring and control system for a hybrid windpv-battery renewable energy system", International Conference on Intelligent Systems Applications to Power Systems, ISAP 2007, Toki Messe, Niigata, November, pp. $1-6$.

[6] W. Carter and B.M. Diong, "Model of a regenerative fuel cell-supported wind turbine ac power generating system", $39^{\text {th }}$ IEEE Industry Applications IAS Annual Meeting Conference, Vol. 4, pp. 2778-2785, 2004.

[7] L. Wang and C. Singh, "PSO-based multidisciplinary design of a hybrid power generation system with statistical models of wind speed and solar insolation", International Power Electronics, Drives and Energy Systems, PEDES'06, December, pp. 1-6, 2006

[8] L. Wang and C. Singh, "Compromise between cost and reliability in optimum design of an autonomous hybrid power system using mixed-integer PSO algorithm", International Conference on Clean Electrical Power, ICCEP'07, Capri, May, pp. 682-689, 2007.

[9] D. Xu, L. Kang, L. Chang and B. Cao, "Optimal sizing of standalone hybrid wind/pv power systems using genetic algorithms", Canadian Conference on Electrical and Computer Engineering, CCECE 2005, Saskatoon, May, pp. 1722-1725, 2005.

[10] A.H. Shahirinia, S.M.M. Tafreshi, A.H. Gastaj and A.R. Moghaddamjoo, "Optimal sizing of hybrid power system using genetic algorithm", International Conference on Future Power Systems, November, 2005.

[11] A. Mestre and J.C. Diehl, "Ecodesign and renewable energy: how to integrate renewable energy technologies into consumer products", Fourth International Symposium on Environmentally Conscious Design and Inverse Manufacturing, December, pp. 282-288, 2005.

[12] D. Das, R. Esmaili, L. Xu and D. Nichols, "An optimal design of a grid connected hybrid wind/photovoltaic/fuel cell system for distributed energy production", $31^{\text {st }}$ Annual Conference of IEEE Industrial Electronics Society, IECON 2005, November, pp. 2499-2504, 2005.

[13] A.A. Ghoneim, "Design optimization of photovoltaic powered water pumping systems", Energy Conversion \& Management, pp. 1449-1463, 2006.

[14] I.H. Altas and A.M. Sharaf, "A novel GUI modeled fuzzy logic controller for a solar powered energy utilization scheme", The 13th International Conference on Emerging Nuclear Energy Systems (ICENES2007), Istanbul, Turkey, June, 2007.

[15] I.H. Altas and A.M. Sharaf, "A photovoltaic array simulation model for Matlab-Simulink GUI environment", International Conference on Clean Electrical Power, ICCEP'07, Capri, Italy, May, 2007.

[16] M.L. Doumbia, K. Agbossou and T.K. Bose, "Islanding protection evaluation of inverter-based grid-connected hybrid renewable energy system", Canadian Conference on Electrical and Computer Engineering, CCECE 2004, Niagara Falls, May, Vol. 2, pp. 1081-1084, 2004.

[17] W.D. Kellogg, M.H. Nehrir, G. Venkataramanan and V. Gerez, "Generation unit sizing and cost analysis for standalone wind, photovoltaic, and hybrid wind/pv systems", IEEE Transaction on Energy Conversion, Vol. 13, No. 1, March, pp. 70-75, 1998.

[18] M.H. Nehrir, "A course on alternative energy wind/pv/fuel cell power generation", IEEE Power Engineering Society General Meeting, June, 2006.

[19] J.T. Bialasiewicz and E. Muljadi, "Analysis of renewableenergy systems using rpm-sim simulator", IEEE Transactions on Industrial Electronics, Vol. 53, No. 4, August, pp. 1137-1143, 2006.

[20] A.A. Pesaran and M. Keyser, "Thermal characteristics of selected EV and HEV batteries", The Sixteenth Annual Battery Conference on Applications and Advances, Long Beach, California, January, pp. 219-225, 2001.

[21] W. Schmitt, "Modeling and simulation of photovoltaic hybrid energy systems optimization of sizing and control", Conference Record of the Twenty-Ninth IEEE Photovoltaic Specialists Conference, May, pp. 1656-1659, 2002.

[22] I.H. Altas and A.M. Sharaf, "Novel maximum power fuzzy logic controller for photovoltaic solar energy systems", Renewable Energy, doi:10.1016/j.renene.2007.03.002, 2007.

[23] I.H. Altas and A.M. Sharaf, "A generalized direct approach for designing fuzzy logic controllers in Matlab/Simulink GUI environment", International Journal of Information Technology and Intelligent Computing, Int. J. IT\&IC No. 4, Vol. 1, 2007. 